\title{
Modulation of nucleotide excision repair in human lymphocytes by genetic and dietary factors
}

\author{
Sabine A. S. Langie ${ }^{1}$, Lonneke C. Wilms ${ }^{1}$, Satu Hämäläinen ${ }^{2}$, Jos C. S. Kleinjans ${ }^{1}$, Roger W. L. Godschalk ${ }^{1}$ \\ and Frederik J. van Schooten ${ }^{1}$. \\ ${ }^{1}$ Department of Health Risk Analysis and Toxicology, Nutrition and Toxicology Research Institute Maastricht (NUTRIM), \\ Maastricht University, Maastricht 6200 MD, The Netherlands \\ ${ }^{2}$ Centre of Expertise for Health and Work Ability, Finnish Institute of Occupational Health, Helsinki FI-00250, Finland
}

(Received 3 March 2009 - Revised 14 August 2009 - Accepted 17 August 2009 - First published online 2 November 2009)

Gene-environment interactions determine inter-individual variations in nucleotide excision repair (NER) capacity. Oxidative stress was previously found to inhibit NER, thus supplementation with dietary antioxidants could prevent this inhibition, especially in genetically susceptible subjects. To study the effects of genetic polymorphisms in NER-related genes and dietary intake of antioxidants on an individual's NER capacity, lymphocytes of 168 subjects were isolated before and after a 4-week blueberry and apple juice intervention. Twelve genetic polymorphisms in NER genes $X P A, X P C, E R C C 1, E R C C 2, E R C C 5, E R C C 6$ and $R A D 23 B$ were assessed by multiplex PCR with single base extension. Based on specific genotype combinations, a subset of individuals ( $n$ 36) was selected for phenotypical assessment of NER capacity, which was significantly affected by the total sum of low-activity alleles $(P=0.027)$. The single polymorphism XPA G23A was the strongest predictor of NER capacity $(P=0 \cdot 002)$; carriers of low-activity alleles AA had about three times lower NER capacity than XPA GG carriers. NER capacity assessed before and after intervention correlated significantly $\left(R^{2} 0.69 ; P<0 \cdot 001\right)$, indicating that inter-individual differences in NER capacity are maintained over 4 weeks. Although the intervention increased plasma trolox equivalent antioxidant capacity from 791 (SE 6.61) to 805 (SE 7.90) $\mu \mathrm{M}(P=0.032)$, on average it did not affect NER capacity. Nonetheless, carriers of twelve or more low-activity alleles seemed to benefit from the intervention $(P=0 \cdot 013)$. Among these, carriers of the variant allele for $R A D 23 B$ Ala249Val showed improved NER capacity upon intervention $(P=0 \cdot 020)$. In conclusion, improved NER capacity upon dietary intervention was detected in individuals carrying multiple low-activity alleles. The XPA G23A polymorphism might be a predictor for NER capacity.

Nucleotide excision repair: Single nucleotide polymorphisms: Dietary modulation

Molecular epidemiological studies have reported large interindividual variations in susceptibility to environmental carcinogens and subsequent cancer risk, which may partly be due to genetically determined variations in nucleotide excision repair (NER) capacity ${ }^{(1-4)}$. The NER pathway protects the integrity of the genome by recognising and eliminating a broad spectrum of bulky lesions such as UV-induced pyrimidine dimers, aromatic DNA adducts, and cross-links. Moreover, several NER-related enzymes have been shown to play a role in the cellular protection against certain types of oxidative DNA damage (including thymine glycols, 8-oxoguanine and cyclodeoxyadenosine), most likely by acting as a cofactor in base excision repair $(B E R)^{(5-7)}$. Thus NER is a versatile DNA repair system, involving the joint action of a variety of enzymes such as XPC-RAD23B, CSB, XPA, $\mathrm{XPF}-\mathrm{ERCC} 1$, and others ${ }^{(8,9)}$. It is clear that NER plays a crucial role in cancer prevention, because defects in this pathway lead to several severe human disorders, such as xeroderma pigmentosum ${ }^{(10)}$. Furthermore, several studies suggest that genetic polymorphisms in various NER genes may have a profound impact on the phenotypical activity of this repair pathway ${ }^{(11-13)}$. In addition, various genetic polymorphisms in DNA-repair genes have been shown to modulate the levels of bulky DNA adducts ${ }^{(11,14,15)}$ or chromosomal damage $^{(16-18)}$. So, a number of studies identified associations between polymorphisms in DNA-repair genes with the amount of DNA damage and the capacity to repair these damages.

Next to the effect of single nucleotide polymorphisms (SNP) on DNA-repair activity, also other factors, such as diet and specific dietary compounds, are thought to modulate DNA-repair capacities. Although there is sufficient evidence for chemopreventive effects of certain dietary compounds $^{(19)}$, only a few studies have reported that dietary compounds influence DNA-repair processes (for a review,

\footnotetext{
Abbreviations: BER, base excision repair; BPDE, benzo[a]pyrene-diolepoxide; ERCC1, excision repair cross-complementing group 1; NER, nucleotide excision repair; RAD23B, RAD23 homologue B (one of two human homologues of Saccharomyces cerevisiae Rad23); SBE, single base extension; SNP, single nucleotide polymorphism; TEAC, trolox equivalent antioxidant capacity; TI, tail intensity; TM, tail moment; XPA, xeroderma pigmentosis, complementation group A; XPC, xeroderma pigmentosis, complementation group C.

* Corresponding author: Dr Frederik J. van Schooten, fax +31 43388 4146, email F.vanSchooten@GRAT.unimaas.nl
} 
see Tyson $\&$ Mathers $\left.{ }^{(20)}\right)$. Several of these studies investigated the dietary modulation of BER or the repair of oxidative lesions. For example, a 3-week intervention with one, two or three kiwi fruits resulted in a significant increase of the BER capacity, as measured by a modified comet assay ${ }^{(21)}$. In fact, to the best of our knowledge, there are only two studies that investigated the effect of dietary factors on NER capacity in human subjects. Wei et al. observed an association between low dietary folate intake and reduced NER capacity $^{(22)}$, while Tyson et al. reported no detectable effect of micronutrient supplementation on NER capacity ${ }^{(23)}$. Therefore, there is an increasing need to study the impact of diet on NER capacity.

We previously showed that especially oxidative stress can inhibit NER capacity ${ }^{(24,25)}$. Thus, enhanced dietary intake of antioxidants may represent an opportunity for improving NER by reducing oxidative stress. Therefore, we studied the dietary modulation of DNA repair by using samples from a 4-week intervention study with healthy volunteers, consuming 1 litre of blueberry and apple juice per $\mathrm{d}^{(26)}$. This intervention was found to be efficient in enhancing antioxidant defence and reducing the levels of ex vivo-induced oxidative DNA damage ${ }^{(26,27)}$. In the present study, we hypothesised that NER capacity is determined by polymorphisms in DNArepair genes and that diet may modulate an individual's NER capacity. Therefore, our aims were to (i) investigate the effect of the blueberry and apple juice intervention on the NER capacity; (ii) determine the effect of genetic polymorphisms in NER genes on the phenotypic NER capacity; (iii) identify possible gene-diet interactions.

\section{Materials and methods}

\section{Study population}

The study population consisted of 168 healthy volunteers, 114 female and fifty-four male, aged 18-45 years (for more details, see references $\left.{ }^{(26,27)}\right)$. Volunteers were recruited through advertisement in local newspapers and were included if they were non-smokers, did not use any medication (except for oral contraceptives) or any vitamin supplementation. The present study was conducted according to the guidelines laid down in the Declaration of Helsinki and all procedures involving human subjects were approved by the Medical Ethical Committee of Maastricht University and the Academic Hospital Maastricht. Written informed consent was obtained from all subjects.

\section{Dietary intervention and study design}

The design of the present intervention as well as the efficacy of the washout period was based on a pilot study, described previously ${ }^{(26,27)}$. Briefly, in a paired design, each subject acted as his or her own control. A $5 \mathrm{~d}$ washout period was followed by an intervention period of 4 weeks with a custom-made blueberry and apple juice mixture, produced specifically for the present study by Riedel Drinks (now Friesland Foods, Ede, The Netherlands), of which subjects consumed 1 litre/d. This blueberry and apple juice mixture was about 1.85 times more concentrated than regular fruit juices of Riedel Drinks, consisting of $135 \%$ blueberry juice and $50 \%$ apple juice. As a consequence, it contained high levels of antioxidants, predominantly in the form of flavonoids. Supplementation with this blueberry and apple juice for 4 weeks was reported to be effective, as the intervention significantly increased total plasma antioxidant capacity (trolox equivalent antioxidant capacity (TEAC); $P<0.001)$ and reduced the levels of $e x$ vivo-induced oxidative DNA damage by $20 \%(P=0.006)^{(26)}$. The impact of seasonal variation in dietary habits or increased sensitivity was overcome by year-round random sampling.

\section{Collection of samples}

After the $5 \mathrm{~d}$ washout period and a second time after the 4-week intervention period, blood samples were obtained between 08.00 and 09.00 hours by venepuncture. Volunteers were allowed to have breakfast before sampling, but no juice. Venous blood samples were obtained into one $10 \mathrm{ml}$ EDTA vacuum tube for plasma analyses and into two $10 \mathrm{ml}$ vacuum lithium heparin tubes (venoject II; Terumo-Europe, Leuren, Belgium) for isolation of lymphocytes. The EDTA tubes were centrifuged for $10 \mathrm{~min}$ at $265 \mathrm{~g}$ at $4{ }^{\circ} \mathrm{C}$ to separate plasma for the analysis of the total plasma antioxidant capacity (TEAC) as described previously ${ }^{(26)}$. All plasma samples were kept at $-80^{\circ} \mathrm{C}$ until analysis. Lymphocytes were isolated using a standard density gradient centrifugation method $^{(28)}$, sampled and stored as cell pellets at $-20^{\circ} \mathrm{C}$. One sample was used to isolate DNA for genotyping purposes, using standard phenol extraction procedures. Another lymphocyte sample was used to prepare protein extracts to phenotypically assess NER capacity.

\section{Selection of polymorphisms for genotyping}

In the present study, twelve SNP in NER genes (Table 1) were selected on the basis of (a) their association with cancer development, or (b) their expected influence on DNA repair based on literature review. DNA sequences and allele frequencies were obtained from the Cancer SNP 500 database (http:// snp500cancer.nci.nih.gov). Of the twelve SNP analysed here, two have been described before by Wilms et al. ${ }^{(26)}$. In order to genotype the remaining ten SNP (Table 2) we further developed the multiplex PCR method. The development and validation of the adapted multiplex PCR for the new set of ten SNP in various NER genes was based on an approach as described before ${ }^{(29)}$. The adapted procedure is defined in the following paragraphs.

\section{PCR primer design and multiplex PCR amplification}

Primer 3 software (http://www.broad.mit.edu/cgi-bin/primer/ primer3_www.cgi) and Netprimer software (http://www. premierbiosoft.com/netprimer/netprlaunch/netprlaunch.html) were used to design PCR primers (for more detailed information, see Knaapen et al. $\left.{ }^{(29)}\right)$. Primers were obtained from Qiagen. First, the isolated DNA containing SNP was amplified in one eightplex and one duplex PCR reaction. For the eightplex PCR, a $10 \mu \mathrm{l}$ reaction mixture was prepared containing PCR buffer, $10 \mathrm{~mm}$-deoxynucleotide triphosphates, $50 \mathrm{~mm}-\mathrm{MgCl}_{2}$, Platinum ${ }^{\circledR}$ Taq Polymerase (5 U/ $\mu$; Invitrogen, Carlsbad, CA, USA) and template DNA (40 ng/ $\mu \mathrm{l})$. The final primer concentrations were $2.0 \mu \mathrm{M}$ (for $X P C-03, E R C C 6-01, E R C C 1-05$, ERCC1-06 and ERCC1-30), 0.8 $\mu \mathrm{M}$ (for XPA-02), $1.6 \mu \mathrm{M}$ 
Table 1. Overview of single nucleotide polymorphisms (SNP) included in the present study and their expected effects on DNA-repair capacity

\begin{tabular}{|c|c|c|c|c|c|c|}
\hline $\mathrm{SNP}^{*}$ & $\begin{array}{l}\text { Amino acid } \\
\text { change }\end{array}$ & $\begin{array}{l}\text { Changed } \\
\text { base }\end{array}$ & Function within NER & $\begin{array}{l}\text { Expected effect of variant } \\
\text { allele on NER capacity }\end{array}$ & References & $\begin{array}{l}\text { Activity alleles } \\
\quad(0 / 1 / 2) \dagger\end{array}$ \\
\hline$X P A-02$ & $5^{\prime}$-UTR & $\mathrm{G} \rightarrow \mathrm{A}$ & $\begin{array}{l}\text { Second step of damage recognition (GGR and TCR); binds, stabilises } \\
\text { open complex; confirms damage; recruits RPA, ERCC1 }\end{array}$ & Less efficient NER capacity & $10,42,48,49$ & GG/GA/AA \\
\hline$X P C-01$ & Lys939GIn & $A \rightarrow C$ & $\begin{array}{l}\text { Initial damage recognition; binds lesion in complex with RAD23B } \\
\text { (GGR); causes local unwinding; recruits other NER proteins }\end{array}$ & $\begin{array}{l}\text { Reduced repair, higher } \\
\text { adduct levels }\end{array}$ & $2,9,48,52,53$ & $\mathrm{AA} / \mathrm{AC} / \mathrm{CC}$ \\
\hline$X P C-03$ & Ala499Val & $\mathrm{C} \rightarrow \mathrm{T}$ & $\begin{array}{l}\text { Initial damage recognition; binds lesion in complex with RAD23B } \\
\text { (GGR); causes local unwinding; recruits other NER proteins }\end{array}$ & $\begin{array}{l}\text { Increased repair, lower } \\
\text { adduct levels }\end{array}$ & 9,54 & $\mathrm{TT} / \mathrm{CT} / \mathrm{CC}$ \\
\hline$E R C C 1-05$ & Asn118Asn & $\mathrm{T} \rightarrow \mathrm{C}$ & $\begin{array}{l}\text { Forms a heterodimeric protein complex with XPF (also known as } \\
\text { ERCC4); endonuclease }-5^{\prime} \text { incision (GGR and TCR) }\end{array}$ & Higher NER capacity & $38,42,44$ & $\mathrm{CC} / \mathrm{TC} / \mathrm{TT}$ \\
\hline ERCC1-06 & Intron 3 & $\mathrm{G} \rightarrow \mathrm{C}$ & $\begin{array}{l}\text { Forms a heterodimeric protein complex with XPF (also known as } \\
\text { ERCC4); endonuclease }-5^{\prime} \text { incision (GGR and TCR) }\end{array}$ & More efficient repair & 55 & $\mathrm{CC} / \mathrm{GC} / \mathrm{GG}$ \\
\hline ERCC1-30 & GIn504Lys & $\mathrm{G} \rightarrow \mathrm{T}$ & $\begin{array}{l}\text { Forms a heterodimeric protein complex with XPF (also known as } \\
\text { ERCC4); endonuclease }-5^{\prime} \text { incision (GGR and TCR) }\end{array}$ & Lower NER capacity & $38,42,43$ & $\mathrm{GG} / \mathrm{GT} / \mathrm{TT}$ \\
\hline ERCC2-02 & Asp312Asn & $\mathrm{G} \rightarrow \mathrm{A}$ & $\begin{array}{l}\text { Also known as XPD protein; } 5^{\prime} \text { to } 3^{\prime} \text { helicase (GGR and TCR); } \\
\text { part of the general transcription complex TFIIH; late DNA } \\
\text { unwinding }\end{array}$ & $\begin{array}{l}\text { Lower NER capacity, higher } \\
\text { adduct levels }\end{array}$ & $38,42,52,56,58$ & GG/GA/AA \\
\hline ERCC2-03 & Lys751Gln & $A \rightarrow C$ & $\begin{array}{l}\text { Also known as XPD protein; } 5^{\prime} \text { to } 3^{\prime} \text { helicase (GGR and TCR); } \\
\text { part of the general transcription complex TFIIH; late DNA } \\
\text { unwinding }\end{array}$ & $\begin{array}{l}\text { Lower NER capacity, higher } \\
\text { adduct levels }\end{array}$ & $12,38,42,43,52,53,56-58$ & $\mathrm{AA} / \mathrm{AC} / \mathrm{CC}$ \\
\hline ERCC2-06 & Arg156Arg & $C \rightarrow A$ & $\begin{array}{l}\text { Also known as XPD protein; } 5^{\prime} \text { to } 3^{\prime} \text { helicase (GGR and TCR); } \\
\text { part of the general transcription complex TFIIH; late DNA } \\
\text { unwinding }\end{array}$ & Less efficient NER capacity & 57,59 & $\mathrm{CC} / \mathrm{CA} / \mathrm{AA}$ \\
\hline ERCC5-01 & His46His & $\mathrm{C} \rightarrow \mathrm{T}$ & $\begin{array}{l}\text { Also known as XPG protein (GGR and TCR); endonuclease }-3^{\prime} \\
\text { incision; stabilises full open complex }\end{array}$ & More efficient NER capacity & 42,44 & $\mathrm{TT} / \mathrm{CT} / \mathrm{CC}$ \\
\hline ERCC6-01 & Met1097Val & $A \rightarrow G$ & $\begin{array}{l}\text { Also known as CSB protein (TCR); recruits repair proteins such as } \\
\text { TFIIH; displaces stalled transcription complex so that NER proteins } \\
\text { can enter }\end{array}$ & Less efficient NER capacity & 40,60 & $\mathrm{AA} / \mathrm{AG} / \mathrm{GG}$ \\
\hline$R A D 23 B-04$ & Ala249Val & $\mathrm{C} \rightarrow \mathrm{T}$ & $\begin{array}{l}\text { Initial damage recognition; binds lesion in complex with XPC (GGR); } \\
\text { causes local unwinding; recruits other NER proteins }\end{array}$ & $\begin{array}{l}\text { Less efficient NER capacity, } \\
\text { higher adduct levels }\end{array}$ & 2,3 & $\mathrm{CC} / \mathrm{CT} / \mathrm{TT}$ \\
\hline
\end{tabular}

NER, nucleotide excision repair; XPA, xeroderma pigmentosis, complementation group A; UTR, untranslated region; GGR, global genome repair; TCR, transcription-coupled repair; RPA, replication protein 1; ERCC1, excision repair cross-complementing group 1; XPC, xeroderma pigmentosis, complementation group C; RAD23B, RAD23 homologue $\mathrm{B}$ (one of two human homologues of Saccharomyces cerevisiae Rad23); XPF, xeroderma pigmentosis, complemention excision repair cross-complementing group 5, XPG, xeroderma pigmentosis, complementation group $G$, ERCC6, excision repair cross-complementing group 6; CSB, Cockayne syndrome $B$.

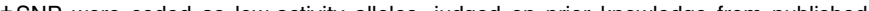

literature and their expected modulating effect on the NER capacity: $0=$ homozygous for high-activity allele; $1=$ heterozygous, carrying one high- and one low-activity allele; 2 = homozygous for low-activity allele. 
Table 2. Overview of single nucleotide polymorphisms (SNP) included in the modified multiplex PCR, together with their PCR and single base extension (SBE) primers

\begin{tabular}{|c|c|c|c|c|c|}
\hline SNP $^{*}$ & dbSNP ID* & PCR primers & $\begin{array}{l}\text { Product } \\
\text { (bp) }\end{array}$ & SBE primers $†$ & $\begin{array}{l}\text { Length } \\
\text { (bp) }\end{array}$ \\
\hline \multicolumn{6}{|c|}{ Run in an eightplex PCR } \\
\hline$X P A-02$ & rs1800975 & $\begin{array}{l}\text { Forward 5'-GCAGGCGCTCTCACTCAGAA-3' } \\
\text { Reverse 5'-TGCCGCTTCCGCTCGATA-3' }\end{array}$ & 230 & 5'-AACTCGGCCGCCGCCATCTC-3' & 20 \\
\hline$X P C-01$ & rs2228001 & $\begin{array}{l}\text { Forward 5'-GCCTCAAAACCGAGAAGATG-3' } \\
\text { Reverse } 5^{\prime} \text {-AGGTGTGGGGCCTGTAGTG-3' }\end{array}$ & 178 & 5'-AACTGACTATACTACGGCTTCCCACCTGTTCCCATTTGAG-3' & 40 \\
\hline$X P C-03$ & rs2228000 & $\begin{array}{l}\text { Forward 5'-GGTCCAAGAGTGCCTCCAG-3' } \\
\text { Reverse 5'-TTCTGCCTTCTCACCATCG-3' }\end{array}$ & 132 & 5'-AACTGACTAAACTGCTTGAAGAGCTTGAGGATGCC-3' & 35 \\
\hline ERCC6-01 & rs2228526 & $\begin{array}{l}\text { Forward 5'-AATCTGAGGCTAAAGGAGCTGA-3' } \\
\text { Reverse } 5^{\prime} \text {-TCTTCTCCAAGCCTATCATTGC- } 3^{\prime}\end{array}$ & 119 & 5'-AACACACTAAACCAAGCCTATCATTGCTAGTTACATTACTACTCA-3' & 45 \\
\hline ERCC1-05 & rs11615 & $\begin{array}{l}\text { Forward 5'-TCCCTATTGATGGCTTCTGC- } 3^{\prime} \\
\text { Reverse } 5^{\prime} \text {-CTCTGGCCCAGCACATAGTC- } 3^{\prime}\end{array}$ & 124 & 5'-AACTGACTAAACTAGCTGTTACGTCACGAATCGCCAAATTCCCAGGGCAC-3' & 50 \\
\hline$E R C C 1-06$ & rs3212948 & $\begin{array}{l}\text { Forward 5'-GAGGAGGGAGACGGAGAAGT-3' } \\
\text { Reverse } 5^{\prime} \text {-CACTGCTGTCGAATGAATGAA-3' }\end{array}$ & 149 & 5'-AACTGTCTATACTACGTGTTCGCAACAGATAGTGGCTGGAACTCAGACCTCCTT-3' & 54 \\
\hline ERCC1-30 & rs3212986 & $\begin{array}{l}\text { Forward 5'-GGGCACCTTCAGCTTTCTTT- } 3^{\prime} \\
\text { Reverse } 5^{\prime} \text {-AATTCAGAGTCTGGGGAGGAG-3' }\end{array}$ & 124 & 5'-AACTGACTAAACTAGGTGACTCGTCGTGAAAGTCTCTACACAGGCTGCTGCTGCTGCT-3' & 58 \\
\hline RAD23B-04 & rs1805329 & $\begin{array}{l}\text { Forward 5'-GAGAAAGTCAGGCTGTGGTTG-3' } \\
\text { Reverse } 5^{\prime} \text {-GATTCCGCTTTACCTCCAGA-3' }\end{array}$ & 137 & 5'-AACTGACTAAACTAGGTGCCATGTCGTGAATGTCTGACACAGCCACTGCTGAAGACTGAGGA-3' & 62 \\
\hline \multicolumn{6}{|c|}{ Run in a duplex PCR } \\
\hline ERCC2-02 & rs1799793 & $\begin{array}{l}\text { Forward 5'-CCGCAGGATCAAAGAGACAGA-3' } \\
\text { Reverse 5'-AAGCCCAGGAAATGCTCG-3' }\end{array}$ & 265 & 5'-AACTGACTGGCTCACCCTGCAGCACTTCGT-3' & 30 \\
\hline ERCC5-01 & rs1047768 & $\begin{array}{l}\text { Forward 5'-TCTCCCAGATATTAGCATTTGGTT-3' } \\
\text { Reverse 5'-TTTGCAGAGCCGATGAAAC-3 }\end{array}$ & 116 & 5'-AAGATGAGGATTTTCTATTGAGTTCCC-3' & 27 \\
\hline
\end{tabular}

$X P A$, xeroderma pigmentosis, complementation group A; XPC, xeroderma pigmentosis, complementation group C; ERCC6, excision repair cross-complementing group 6; ERCC1, excision repair cross-complementing group 1; $R A D 23 B, \mathrm{RAD23}$ homologue B (one of two human homologues of Saccharomyces cerevisiae Rad23); ERCC2, excision repair cross-complementing group 2; ERCC5, excision repair cross-complementing group 5.

* According to the Cancer SNP 500 database (http://snp500cancer.nci.nih.gov).

† Neutral non-homologous, non-binding tails are underlined. 
(for $X P C$-01) and $4.0 \mu \mathrm{M}$ (for $R A D 23 B-04$ ). For the duplex PCR, the final primer concentrations were $2.7 \mu \mathrm{M}$ (for $X P D-02$ ) and $12.3 \mu \mathrm{M}$ (for $E R C C 5-01$ ) (for corresponding rs-numbers and PCR primers, see Table 2). PCR was conducted as follows: denaturation at $94^{\circ} \mathrm{C}$ for $3 \mathrm{~min}$; thirty cycles of $94^{\circ} \mathrm{C}$ for $30 \mathrm{~s}$, $63^{\circ} \mathrm{C}$ for $30 \mathrm{~s}$, and $72^{\circ} \mathrm{C}$ for $30 \mathrm{~s}$; and a final extension at $72^{\circ} \mathrm{C}$ for $5 \mathrm{~min}$. After PCR amplification, the products were pooled ( $5 \mu \mathrm{l}$ of the eightplex and $3 \mu \mathrm{l}$ of the duplex PCR product) and incubated $\left(37^{\circ} \mathrm{C}\right.$ for $\left.45 \mathrm{~min}\right)$ with $4 \mu \mathrm{l}$ of ExoSAP-IT (Amersham, Roosendaal, The Netherlands) to digest residual deoxynucleotide triphosphates and primers. Enzymes were deactivated at $75^{\circ} \mathrm{C}(15 \mathrm{~min})$.

\section{Multiplex genotyping}

Genotyping was performed by single base extension (SBE) using SnaPShot ${ }^{\mathrm{TM}}$ as described by the manufacturer (Applied Biosystems, Nieuwerkerk a.d. IJssel, The Netherlands), with some modifications. Briefly, SBE primers were designed using Primer 3 and Netprimer software to bind immediately adjacent $5^{\prime}$ to the specific SNP, with a template-specific part of 20 to $33 \mathrm{bp}$ and a $\mathrm{T}_{\mathrm{m}}$ of $66^{\circ} \mathrm{C}$ to $69^{\circ} \mathrm{C}$ (Table 2). To facilitate detection of ten polymorphisms in one single run, the length of the extension primers was adjusted to a distinct size by the addition of a non-homologous tail to their $5^{\prime}$ side $^{(29)}$. To this end, $5 \cdot 5 \mu$ l of the purified PCR product (containing eleven fragments) were mixed with $2.5 \mu \mathrm{l}$ of SNaPshot reaction mixture, $1 \mu$ l of pooled SBE primers and $1 \mu \mathrm{l}$ of water. The final concentration for all SBE primers was $4 \mu \mathrm{M}$, except for $X P A-02$ and ERCC5-01 (2 $\mu \mathrm{M})$. SBE was performed using twenty-five cycles of $96^{\circ} \mathrm{C}$ for $10 \mathrm{~s}$ and $60^{\circ} \mathrm{C}$ for $30 \mathrm{~s}$. Subsequently, the samples were incubated at $37^{\circ} \mathrm{C}$ for $1 \mathrm{~h}$ with $1 \mathrm{U}$ of shrimp alkaline phosphatase (Amersham, Roosendaal, The Netherlands), followed by enzyme deactivation at $75^{\circ} \mathrm{C}$ for $15 \mathrm{~min}$. The SBE products were finally analysed by capillary electrophoresis, for which $1 \mu \mathrm{l}$ of the (fivefold-diluted) SBE product were mixed with $13 \mu \mathrm{l}$ of deionised formamide and $0.4 \mu \mathrm{l}$ of Genescan-120 LIZ $^{\mathrm{TM}}$ size marker (Applied Biosystems, Foster City, CA, USA). Samples were denatured at $95^{\circ} \mathrm{C}$ for $5 \mathrm{~min}$ and run on an ABI-Prism ${ }^{\circledR} 3100$ genetic analyser using a $36 \mathrm{~cm}$ capillary array and POP-6 polymer. Analyses were performed with Genescan $^{\text {TM }}$ software (version. 3.7; Applied Biosystems) ${ }^{(29)}$.

\section{Measurement of nucleotide excision repair capacity}

A subpopulation of thirty-six healthy volunteers (twenty-eight female and eight male, aged 18-45 years) was selected for the phenotypical assessment of NER. Since we previously observed that ERCCI expression could be a proxy for NER capacity $^{(24)}$, selection of subjects occurred according to their ERCC1 genotype. More specifically, samples from homozygous wild types and homozygous carriers of the variant allele for the three studied SNP in ERCCl were selected for DNA-repair analysis (for the number of subjects selected per ERCC1 genotype, see Table 3).

To phenotypically assess the NER capacity in human lymphocytes, we applied a modified comet assay recently developed in our laboratory ${ }^{(30)}$. Basically, this assay measures the ability of a cell or tissue extract to incise substrate DNA containing benzo[a]pyrene-diolepoxide (BPDE)-DNA adducts.
Table 3. Genotype frequencies as observed in the present study populations

\begin{tabular}{|c|c|c|c|c|}
\hline \multirow[b]{3}{*}{ SNP } & \multicolumn{4}{|c|}{ Frequencies } \\
\hline & \multicolumn{2}{|c|}{ Total population } & \multicolumn{2}{|c|}{ Subpopulation } \\
\hline & $n$ & $\%$ & $n$ & $\%$ \\
\hline \multicolumn{5}{|c|}{$X P A 5^{\prime}-U T R(G \rightarrow A)$} \\
\hline GG & 80 & 48 & 17 & 47 \\
\hline GA & 71 & 42 & 14 & 39 \\
\hline AA & 17 & 10 & 5 & 14 \\
\hline \multicolumn{5}{|c|}{ XPC Lys939GIn $(\mathrm{A} \rightarrow \mathrm{C})$} \\
\hline AA & 68 & 40 & 20 & 56 \\
\hline$A C$ & 72 & 43 & 15 & 42 \\
\hline $\mathrm{CC}$ & 28 & 17 & 1 & 3 \\
\hline \multicolumn{5}{|c|}{ XPC Ala499Val $(C \rightarrow T)$} \\
\hline $\mathrm{CC}$ & 89 & 53 & 14 & 39 \\
\hline CT & 66 & 39 & 18 & 50 \\
\hline TT & 13 & 8 & 4 & 11 \\
\hline \multicolumn{5}{|c|}{ ERCC1 Asn118Asn $(\mathrm{T} \rightarrow \mathrm{C})^{*}$} \\
\hline TT & 67 & 40 & 18 & 50 \\
\hline TC & 69 & 41 & 0 & 0 \\
\hline $\mathrm{CC}$ & 32 & 19 & 18 & 50 \\
\hline \multicolumn{5}{|c|}{$E R C C 1$ intron $3(\mathrm{G} \rightarrow \mathrm{C})^{*}$} \\
\hline GG & 73 & 43 & 18 & 50 \\
\hline $\mathrm{GC}$ & 67 & 40 & 0 & 0 \\
\hline $\mathrm{CC}$ & 28 & 17 & 18 & 50 \\
\hline \multicolumn{5}{|c|}{ ERCC1 Gln504Lys $(\mathrm{G} \rightarrow \mathrm{T})^{*}$} \\
\hline GG & 87 & 52 & 18 & 50 \\
\hline GT & 67 & 38 & 5 & 14 \\
\hline TT & 17 & 10 & 13 & 36 \\
\hline \multicolumn{5}{|c|}{ ERCC2 Asp312Asn $(\mathrm{G} \rightarrow \mathrm{A})$} \\
\hline GG & 70 & 42 & 17 & 47 \\
\hline GA & 76 & 45 & 10 & 28 \\
\hline AA & 22 & 13 & 9 & 25 \\
\hline \multicolumn{5}{|c|}{ ERCC2 Lys751GIn $(\mathrm{A} \rightarrow \mathrm{C})$} \\
\hline AA & 56 & 33 & 17 & 47 \\
\hline$A C$ & 85 & 51 & 9 & 25 \\
\hline $\mathrm{CC}$ & 27 & 16 & 10 & 28 \\
\hline \multicolumn{5}{|c|}{ ERCC2 $\operatorname{Arg} 156 \operatorname{Arg}(\mathrm{C} \rightarrow \mathrm{A})$} \\
\hline $\mathrm{CC}$ & 48 & 28 & 13 & 36 \\
\hline $\mathrm{CA}$ & 85 & 51 & 11 & 31 \\
\hline AA & 35 & 21 & 12 & 33 \\
\hline \multicolumn{5}{|c|}{ ERCC5 His46His $(\mathrm{C} \rightarrow \mathrm{T})$} \\
\hline $\mathrm{CC}$ & 57 & 34 & 15 & 42 \\
\hline CT & 84 & 50 & 15 & 42 \\
\hline TT & 27 & 16 & 6 & 17 \\
\hline \multicolumn{5}{|c|}{ ERCC6 Met1097Val $(\mathrm{A} \rightarrow \mathrm{G})$} \\
\hline AA & 109 & 65 & 23 & 64 \\
\hline$A G$ & 49 & 29 & 9 & 25 \\
\hline GG & 10 & 6 & 4 & 11 \\
\hline \multicolumn{5}{|c|}{ RAD23B Ala249Val $(\mathrm{C} \rightarrow \mathrm{T})$} \\
\hline $\mathrm{CC}$ & 101 & 60 & 20 & 56 \\
\hline CT & 60 & 36 & 12 & 33 \\
\hline TT & 7 & 4 & 4 & 11 \\
\hline
\end{tabular}

SNP, single nucleotide polymorphism; $X P A$, xeroderma pigmentosis, complementation group A; UTR, untranslated region; $X P C$, xeroderma pigmentosis, complementation group C; ERCC1, excision repair cross-complementing group 1; ERCC2, excision repair cross-complementing group 2; ERCC5, excision repair cross-complementing group 5; ERCC6, excision repair cross-complementing group 6; RAD23B, RAD23 homologue $B$ (one of two human homologues of Saccharomyces cerevisiae Rad23).

${ }^{*}$ A subpopulation was selected for nucleotide excision repair analysis, according to their ERCC1 genotype. 
Thus, this assay reflects an individual's capacity to recognise and incise damaged DNA, which are important first steps in the NER process. The increase in DNA incisions/breaks, leading to increased tail moments (TM) and percentage DNA in the tail (also known as tail intensity; TI), is indicative of the NER capacity of the cell extracts. After subtracting background levels from all data, the final repair capacity was calculated according to Langie et al. ${ }^{(30)}$. Analyses were performed in duplicate and samples of the same subject isolated before and after the intervention were paired for analysis. Nucleoids exposed to $3 \mu \mathrm{M}$-BPDE were used as positive controls to correct for inter-assay variations (TM of BPDEexposed cells ranged between experiments ( $n$ 19) from 1.73 (SE 0.97) to 6.64 (SE 0.77)). Percentage DNA in the tail never exceeded $30 \%$, indicating that the in vitro repair assay in our experiments was not near to saturation.

\section{Statistical analysis}

Differences in DNA-repair capacities and TEAC before and after the intervention were analysed by paired-samples $t$ tests. To investigate the effect of the total number of low-activity alleles on the NER capacity, genotypic polymorphisms were coded as number of low-activity alleles, judged on prior knowledge from published literature and their expected modulating effect on the NER capacity (Table 1): 0 (homozygous for high-activity allele); 1 (heterozygous, carrying one highand one low-activity allele); 2 (homozygous for low-activity allele) (similar approach as previously reported by Ketelslegers et al. $\left.{ }^{(31)}\right)$. Subsequently, the total sum of low-activity alleles was computed and related to NER capacity using linear regression analysis. For obtaining sufficient numbers per group $(n \geq 3)$ and subsequent optimal statistical analysis, carriers of five, six, seven or eight low-activity alleles were grouped as carriers of less than nine low-activity alleles. For the same reason, carriers of thirteen, fourteen, fifteen or sixteen low-activity alleles were grouped as carriers of more than twelve low-activity alleles. Stepwise multivariate, linear regression was used to assess the impact of sex, age, TEAC and various polymorphisms on the phenotypically assessed NER capacity. The relationship between NER capacity before and after intervention was assessed by linear regression. Statistical analysis was performed using SPSS (version 15.0; SPSS, Inc., Chicago, IL, USA). In each case, mean values with their standard errors are presented and $P<0.05$ was considered statistically significant.

\section{Results}

\section{Single nucleotide polymorphisms and genotype frequencies}

In Table 1, all analysed SNP, amino acid and base changes related to the polymorphism and the expected effect of the variant allele on the NER capacity are listed. Furthermore, the frequencies of the wild-type, heterozygous and variant alleles as observed in the present study population ( $n$ 168) are represented in Table 3. Complete genotypes were obtained from all samples and frequencies were in Hardy-Weinberg equilibrium. For validation purposes seventeen of the 168 samples $(10 \%)$ were genotyped twice (eight samples of these seventeen were even genotyped in triplicate) and no differences were found.

\section{Effects of dietary intervention on the nucleotide excision} repair capacity

The 4-week intervention with blueberry and apple juice was reported to be effective in the total study population $\left(\begin{array}{ll}n & 168\end{array}\right)^{(26)}$. The mean TEAC value was significantly $(P<0 \cdot 001)$ increased by the intervention from 781 (SE 3.95) to 800 (SE 4.02) $\mu \mathrm{M}$. Similar results were found for the selected subpopulation ( $n$ 36); mean TEAC values were significantly elevated $(P=0.032)$ from 791 (SE 6.61) to 805 (SE 7.90) $\mu \mathrm{M}$. However, when studying the effect of the dietary intervention on NER capacity, no clear effects of the 4-week blueberry and apple juice intervention on the phenotypically assessed NER capacity and no significant correlations between NER capacity and TEAC values were observed. NER capacity measured as TM before the intervention correlated strongly with the NER capacity detected after the intervention (Fig. 1). Similar results were obtained by using TI as a readout $\left(R^{2} 0.79 ; P<0.001\right.$; slope 0.97).

\section{Effects of genetic factors on the nucleotide excision repair capacity}

As a first approach to investigate the influence of the genetic profile on the phenotypic NER capacity, the total sum of putative low-activity alleles was calculated and related to the NER capacity assessed before the dietary intervention. A significant inverse correlation between the amount of low-activity alleles and the NER capacity was observed, when repair capacity was calculated by using TM values (Fig. 2(a)) as well as when TI values were used (Fig. 2(b)).

The impact of all single genetic polymorphisms, as well as age and sex, on NER capacity was assessed by stepwise multivariate linear regression analysis. Sex and age had no effect on

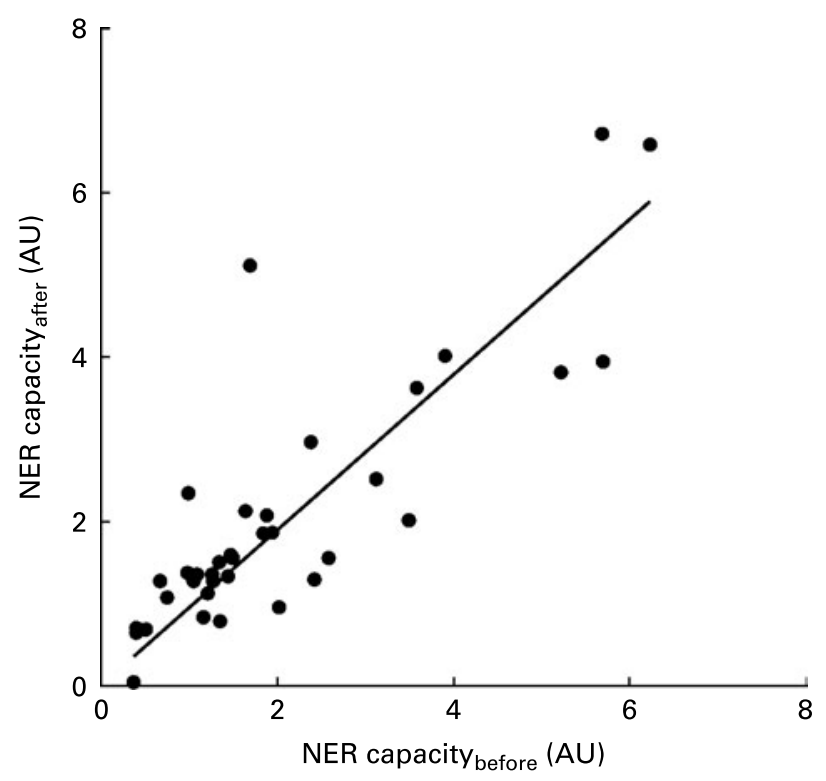

Fig. 1. Correlation between the nucleotide excision repair (NER) capacities measured before and after the blueberry and apple juice intervention $\left(R^{2} \quad 0.69 ; P<0.001 ;\right.$ slope 0.95$)$. Data are presented as the mean of each individual's repair capacity, calculated based on tail moment values. $\mathrm{AU}$, arbitrary units. 
NER, while the single genetic polymorphism XPA G23A was revealed to be a significant predictor of the NER capacity (Fig. 3(a) and (c)) before the intervention. Individuals that were homozygous for the variant allele of XPA G23A $(n 5)$ showed a about three times lower NER capacity as compared with those carrying the homozygous wild-type alleles ( $n 17)$. This association, between NER capacity and the SNP XPA G23A, was not affected by the blueberry and apple juice intervention (Fig. 3(b) and (d)).
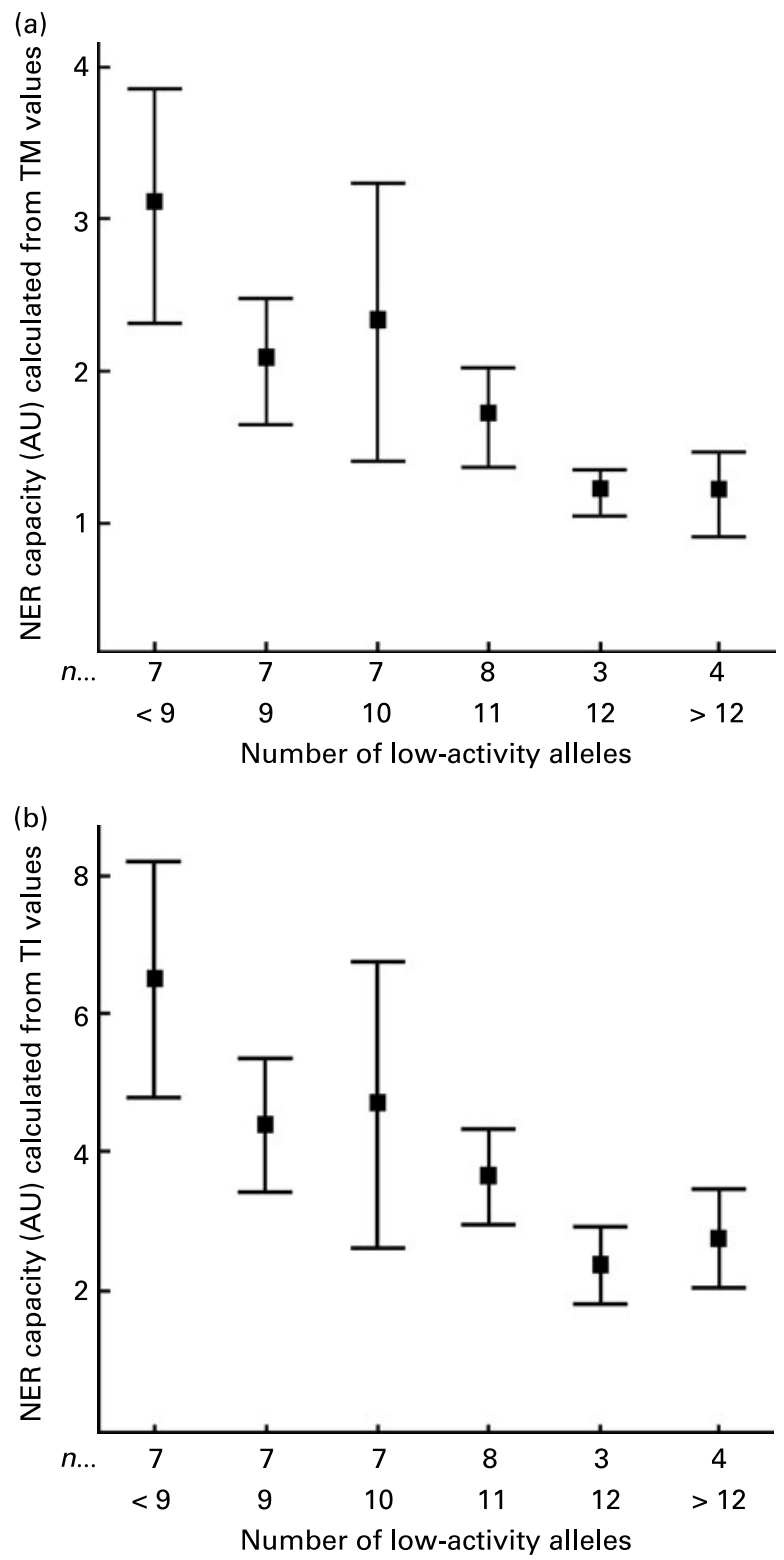

Fig. 2. Relationship between the nucleotide excision repair (NER) capacity and the sum of low-activity alleles in NER-related genes, before intervention. The sum of low-activity alleles was computed for each individual by adding the number of alleles that putatively have adverse effects on NER capacity (Table 1). An increase in this sum of total low-activity alleles was associated with a decreased NER capacity, as calculated (a) from tail moment (TM) values $\left(R^{2} 0.14 ; P=0.027\right)$ as well as (b) from tail intensity ( $\left.\mathrm{TI}\right)$ data $\left(R^{2} 0.12 ; P=0.041\right)$. Data are means, with standard errors represented by vertical bars. $\mathrm{AU}$, arbitrary units.

\section{Gene-diet interactions}

Although the diet did not affect the repair capacity in general, it can be postulated that individuals with a certain genetic background may show an altered NER capacity due to the blueberry and apple juice intervention. To study possible gene-diet interactions regarding changes in NER capacity, differences between the NER capacities measured after and before the intervention were calculated for each individual $\left(\Delta\right.$ NER capacity $=$ NER capacity $_{\text {after }}-$ NER capacity $\left._{\text {before }}\right)$. Based on calculations using TM values, improved NER capacity was detected upon dietary intervention in individuals carrying multiple low-activity alleles (Fig. 4(a)); a mean $\Delta$ NER capacity of $-0 \cdot 15$ (SE $0 \cdot 13$ ) was observed for carriers of eleven or fewer low-activity alleles ( $n$ 29), which increased to a mean $\Delta$ NER capacity of 0.36 (SE 0.51$)$ and 0.96 (SE 1.64) for carriers of twelve ( $n$ 3) and more than twelve $(n 4)$ lowactivity alleles, respectively. Similar results were obtained by using TI as a read-out of the NER capacity (Fig. 4(b)); carriers of eleven or fewer low-activity alleles ( $n$ 29) showed a mean $\triangle$ NER capacity of -0.29 (SE 0.25), which increased to 0.87 (SE 1.04) and 1.63 (SE 1.36) for carriers of twelve (n 3) and more than twelve ( $n$ 4) low-activity alleles, respectively. It should be noted here, however, that the effects of the dietary intervention on the NER phenotype was considerably smaller than the effect of the genotype alone.

Furthermore, this $\triangle N E R$ capacity as an indicator of the intervention effect was tested by multiple stepwise linear regression analysis against all individual SNP, $\triangle \mathrm{TEAC}$, age and sex. No effects of sex, age and $\triangle$ TEAC were observed. However, the intervention differentially affected $\triangle \mathrm{NER}$ capacity in subjects that carried the RAD23B Ala249Val polymorphism (Fig. 5); homozygous carriers of the low-activity Val-allele $(n 4)$ benefited more from the intervention by a significantly increased NER capacity as compared with subjects homozygous for the wild-type/high-activity Ala-allele ( $n$ 20). Interestingly, homozygous carriers of the $R A D 23 B$ Val-allele showed about 1.3 times lower NER capacity as their wildtype counterparts (1.49 (SE 0.21) v. 1.93 (SE 0.30) and 2.99 (SE 0.51) v. 4.05 (SE 0.66), when using TM and TI values, respectively) before the intervention, while after intervention about 1.5 and about 1.3 times higher NER capacity compared with homozygous carriers of the wild-type Ala-allele (2.52 (SE 0.92) v. 1.73 (SE 0.23) and 4.88 (SE 1.71) v. 3.70 (SE 0.55), when using TM and TI values, respectively) was observed in these subjects. In other words, improved NER capacity upon dietary intervention was detected in individuals carrying low-activity alleles.

\section{Discussion}

Until now only a few studies have investigated the relationship between genetic polymorphisms in DNA-repair genes and fruit and vegetable intake, mostly in relation to cancer risk and not directly linked to actual repair capacities ${ }^{(32,33)}$. The present study is one of the first to report a joint effect of genetic polymorphisms in NER-related genes and dietary intervention on the phenotypically assessed NER capacity. Twelve genetic polymorphisms in NER-related genes were assessed and related to an individual's phenotypic NER capacity. Furthermore, the effect of a 4-week dietary 
(a)

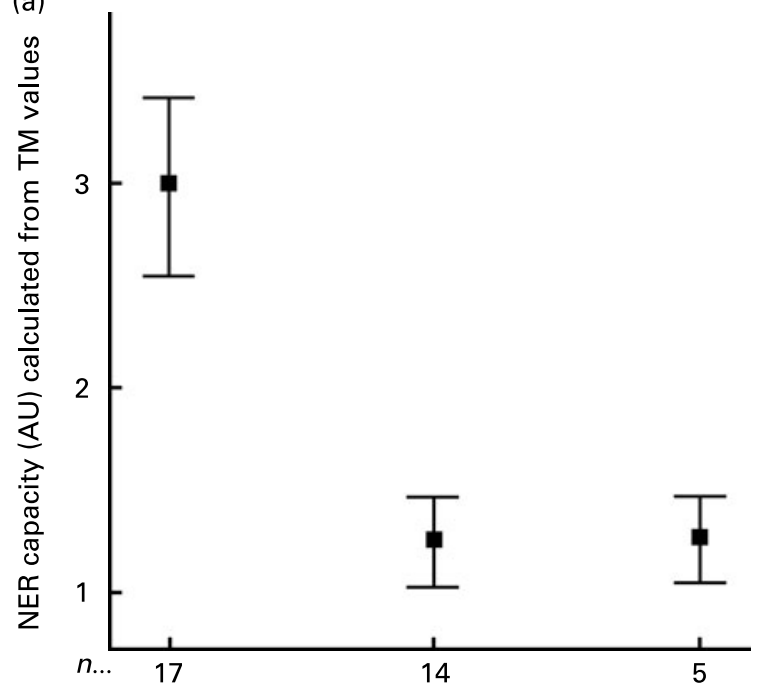

Low-activity

alleles... 0

GG

AG

XPA G23A

(c)

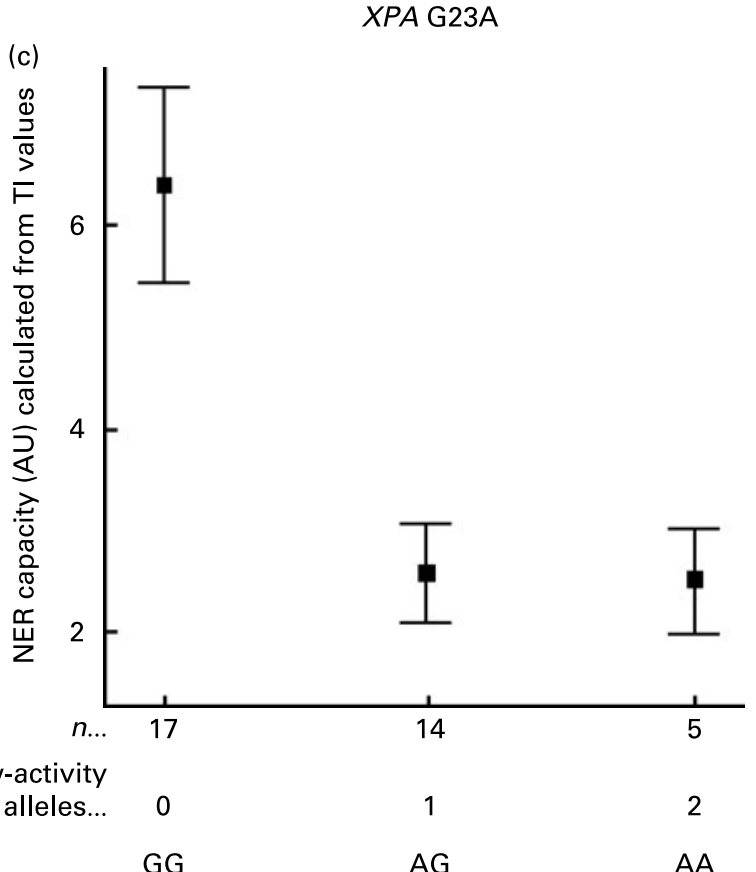

Low-activity

alleles...

\section{2}

AA

1

AG (b)

(b)

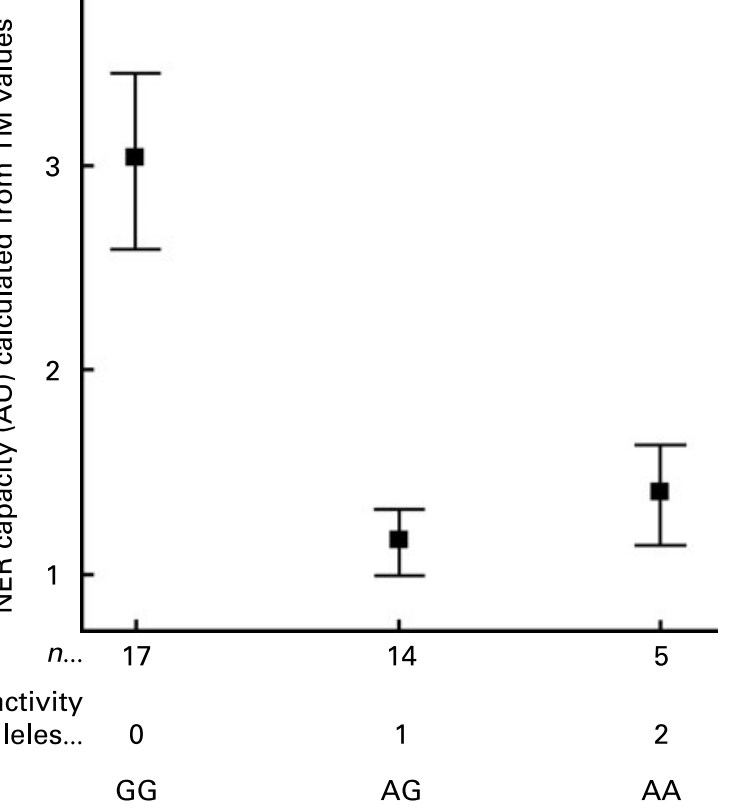

(10)

XPA G23A

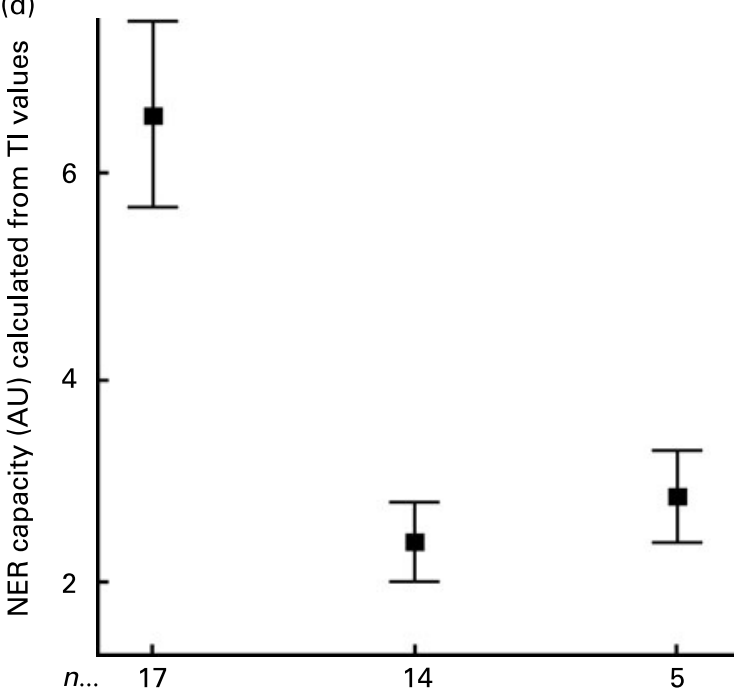

Low-activity

alleles.

GG

1

2

AG

AA

XPA G23A

XPA G23A

Fig. 3. The effect of the xeroderma pigmentosis, complementation group $A(X P A)$ G23A polymorphisms on the phenotypic nucleotide excision repair (NER) capacity. NER capacity calculated from tail moment (TM) values assessed before (a) $(P=0.020)$ and after (b) $(P<0.001)$ the blueberry and apple juice intervention, respectively. NER capacity calculated from tail intensity $(\mathrm{TI})$ values assessed before $(\mathrm{b})(P=0.020)$ and after $(\mathrm{d})(P=0.020)$ the intervention, respectively. Data are means, with standard errors represented by vertical bars. AU, arbitrary units.

intervention with an antioxidant-rich blueberry and apple juice on the phenotypic NER capacity was evaluated and possible genotype-diet interactions were studied. Although the NER capacity was not affected by the dietary intervention in general, carriers of multiple low-activity alleles seemed to benefit from the intervention. Therefore, the present results support the hypothesis that genetic polymorphisms significantly affect NER capacity, which can be further modulated by diet.
In a previous in vitro study ${ }^{(24)}$, we observed that NER capacity was inhibited by oxidative stress. It can thus be postulated that a diet rich in antioxidants may protect NER. However, no overall effects were found in the present intervention study on NER capacity. This is in correspondence with a recent study from Tyson et al. in which they reported no detectable effects of micronutrient supplementation on NER capacity ${ }^{(23)}$. A reasonable explanation for the absence 

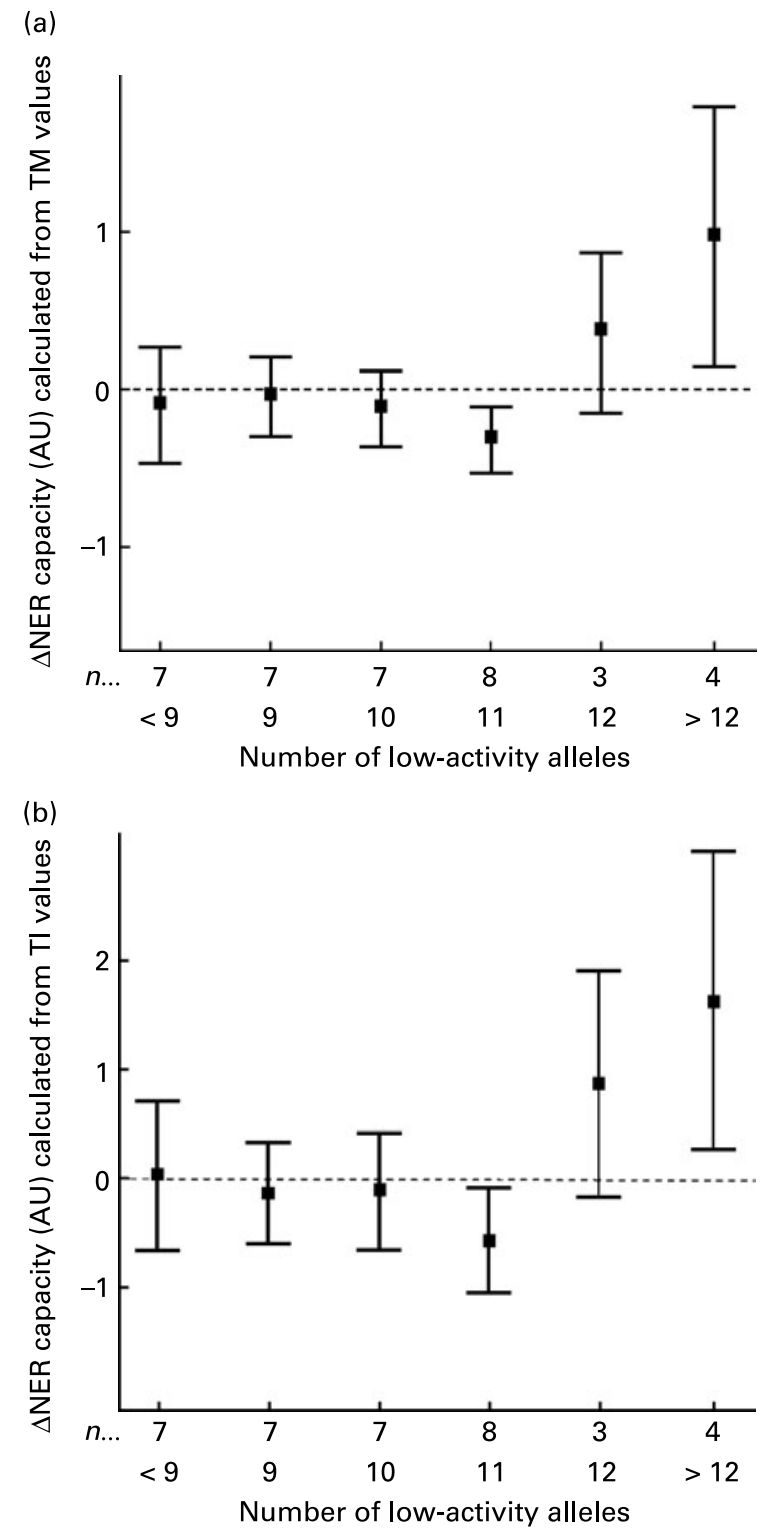

Fig. 4. Relationship between the change in nucleotide excision repair ( $\triangle$ NER) capacity and the sum of low-activity alleles in NER-related genes. The sum of low-activity alleles was computed for each individual by adding the number of alleles that putatively have adverse effects on NER capacity (Table 1). Improved NER capacity was observed in subjects carrying a total sum of low-activity alleles of twelve or more, when either tail moment (TM) $\left(R^{2} 0.17 ; P=0.013\right)$ (a) or tail intensity (TI) $\left(R^{2} 0.14 ; P=0.023\right)$ (b) was used as a read out of the NER capacity. Data are means, with standard errors represented by vertical bars. AU, arbitrary units.

of dietary effects in the present study is that the study population consisted of healthy non-smoking volunteers. Since healthy volunteers encounter relatively low levels of oxidative stress, it may be difficult to detect small additional effects of dietary intake of antioxidants. Future studies on the beneficial effects of diets rich in antioxidants should thus focus on, for instance, subjects suffering from diseases that involve increased oxidative stress. This is supported by observations from previous antioxidant intervention trials with oxidatively stressed subjects (for a review, see Møller \& Loft $^{(34)}$ ). Additionally, in the present intervention study, inter-individual variations in NER capacity were in the range of about 16-fold, which is similar to variations reported previously in human lymphocytes ${ }^{(23,30,35)}$. Moreover, a strong correlation was observed between the NER capacity before and after the supplementation period $\left(R^{2} 0.69, P<0.001\right.$ and $R^{2} 0 \cdot 79, P<0.001$ upon using TM and TI as the read-outs, respectively), indicating that inter-individual variations in NER are maintained over a considerable time, which has been reported before for $\mathrm{NER}^{(23)}$ as well as for $\mathrm{BER}^{(36)}$. In contrast, BER seems to be modifiable by the intake of antioxidants even in healthy subjects ${ }^{(21)}$, but data are not consistent $^{(34,37)}$

Our second aim was to further elucidate the genotypephenotype relationships with respect to the NER process. Although the majority of genes encoding proteins involved in DNA-repair processes are polymorphic ${ }^{(38)}$, only a limited number of studies have examined the actual phenotypic effects of these genetic polymorphisms. In one of our previous studies, we observed a significant correlation between the ERCC1 expression and the phenotypic NER capacity in vitro ${ }^{(24)}$. ERCC1 encodes a subunit of the NER complex, which is required for the incision step of $\mathrm{NER}^{(8,9)}$. However, we did not observe any significant correlation of the studied ERCC1 polymorphisms with the NER capacity in the present study. Since the functional relevance of SNP in ERCC1 remains unclear and inconsistent results have been reported $^{(39,40)}$, further investigation into the effect of these polymorphisms on DNA repair is needed.

On the other hand, subjects carrying a high number of putatively low-activity alleles showed lower NER capacity as compared with subjects carrying only a few low-activity alleles. This approach, looking at the combined effect of multiple gene variants rather than investigating the effect of a single nucleotide polymorphism, has been applied before: several studies have reported an association between the number of putatively high-risk alleles in DNA-repair genes and levels of bulky DNA adduct ${ }^{(31,41)}$, while others have observed increased cancer risk with increasing number of putative high-risk alleles ${ }^{(42,43)}$. All these observations suggest that, at the individual level, studying the combined effect of multiple gene variants may be important in order to define DNA-repair capacity.

Subsequently, to investigate which polymorphisms may have the highest contribution to the inter-individual variations in NER capacity, multivariate linear regression analysis was performed. The common SNP XPA G23A seemed to be the most relevant polymorphisms for defining NER capacity. Individuals homozygous for the wild-type allele (GG) exhibited a significantly three times higher NER capacity (approximately) compared with carriers of at least one variant allele. The XPA protein is involved in both global genome repair and the transcription-coupled repair pathway of the NER process, playing an essential role in the assembly of the pre-incision complex $^{(9)}$. The common $\mathrm{G} \rightarrow \mathrm{A}$ single-nucleotide substitution in the $5^{\prime}$ untranslated region of the XPA gene is located four nucleotides upstream from the ATG start codon ${ }^{(44)}$. The functional relevance of this SNP is unknown; however, it has been demonstrated that the $5^{\prime}$ untranslated region may regulate gene expression through post-transcriptional control mechanisms $^{(45,46)}$. In addition, several studies have shown that individuals with this $\mathrm{G} \rightarrow$ A substitution in the $5^{\prime}$ untranslated 


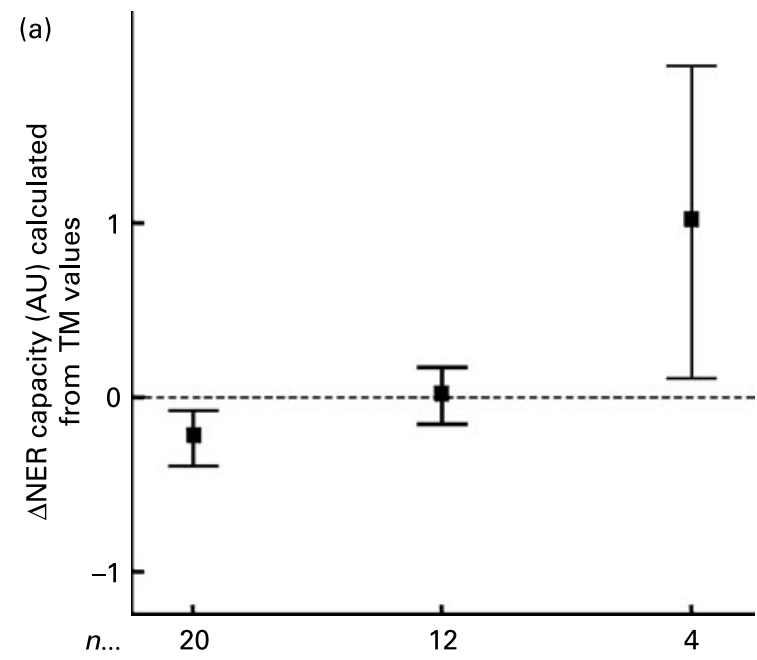

Low-activity

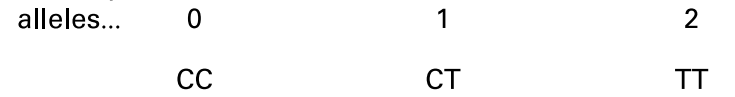

RAD23B Ala249Val

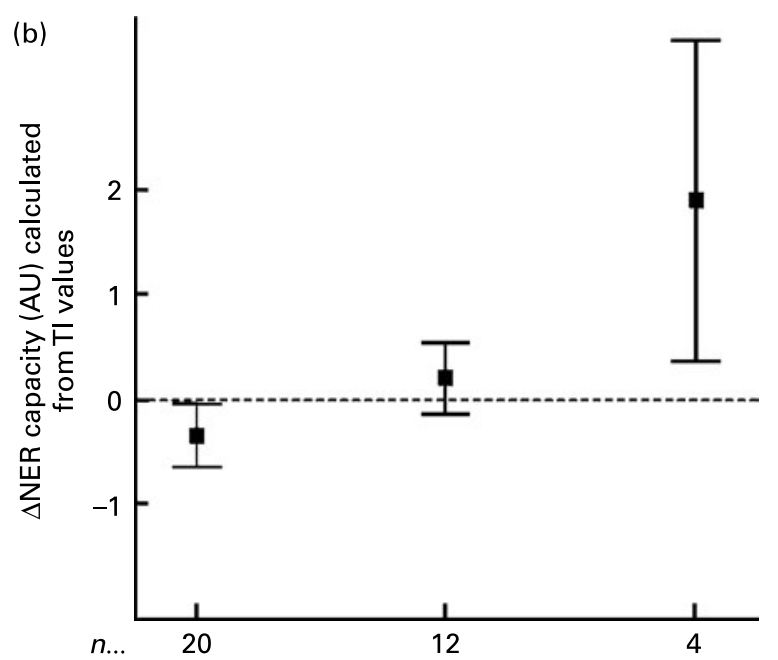

Low-activity alleles... 0 1 2 CC CT TT

\section{RAD23B Ala249Val}

Fig. 5. The influence of the RAD23B Ala249Val polymorphism on the effect of the dietary intervention on the change in nucleotide excision repair $(\Delta \mathrm{NER})$ capacity. Homozygous carriers of the low-activity Val-allele showed an increased $\triangle$ NER capacity as compared with individuals carrying none of the low-activity alleles. (a) $\triangle$ NER capacity calculated from tail moment (TM) values $(P=0.020)$; (b) $\Delta$ NER capacity calculated from tail intensity (TI) values $(P=0.018)$. Data are means, with standard errors represented by vertical bars. $A U$, arbitrary units.

region of $X P A$ have a increased risk of lung cancer ${ }^{(12,47,48)}$. Furthermore, in agreement with the present results, Wu et al. observed a more efficient NER capacity in subjects carrying the $X P A$ GG genotype ${ }^{(12)}$. The association between this $X P A$ polymorphism and NER capacity was not affected by the blueberry and apple juice intervention, indicating that the XPA G23A SNP might be regarded as a predictor for the NER capacity.
Although we initially did not observe an overall effect of diet on NER capacity, it was still possible that a subgroup may benefit from the intervention due to gene-diet interactions. Indeed, enhanced NER capacity was detected in subjects carrying a sum of twelve or more low-activity alleles. Although we did not observe a general effect of the intervention on the NER capacity in our healthy non-smoking study population, we were able to detect a beneficial effect of the intervention in individuals with an initial low NER capacity. Similar observations were reported by Guarnieri et al. detecting beneficial effects of antioxidants only among poorly nourished subjects with low repair activity ${ }^{(49)}$. As mentioned above, future studies on the beneficial effects of diets rich in antioxidants should thus focus more on specific susceptible subpopulations.

Furthermore, the single polymorphism $R A D 23 B$ Ala249Val seemed to be a predictor for the intervention effect $(\triangle N E R$ capacity). Subjects homozygous for the variant Val-allele of $R A D 23 B$ had enhanced NER capacity after the intervention, while NER capacity in carriers of the wild-type Ala-allele was unaffected. Moreover, increased $\triangle$ NER capacity was observed in subjects that carry two low-activity alleles of $R A D 23 B$ Ala249Val. The protein encoded by $R A D 23 B$ binds XPC, forming a heterodimeric complex ${ }^{(9)}$. In the global genome repair pathway XPA binds this protein complex, which is essential for the recruitment of all subsequent NER factors in the pre-incision complex. Although the biological function of the $R A D 23 B$ Ala249Val polymorphism is not clear, the variant alleles $\mathrm{Val} / \mathrm{Val}$ were associated with increased lung cancer risk and higher BPDE sensitivity as compared with the homozygous Ala/Ala wild types ${ }^{(2,3)}$, which is in agreement with the low NER capacity that we detected before the intervention in homozygous carriers of the Val-allele. However, these data need to be interpreted with care, because the group of subjects homozygous for the $R A D 23 B$ Val-allele is small $(n 4)$, and all carried a high number of low-activity alleles. In other words, improved NER capacity upon dietary intervention was especially detected in individuals carrying a high number of low-activity alleles. Nonetheless, our observations suggest that both genetic as well as environmental factors such as diet can modulate an individual's NER capacity, separately or through interaction with each other.

It is not yet clear how this interaction between the genotype and antioxidant intake can be explained. Several studies have suggested that some dietary antioxidants may confer protective properties through mechanisms that are unrelated to their conventional free-radical scavenging abilities, such as up-regulation of antioxidant defence, xenobiotic metabolism or DNA-repair genes ${ }^{(50,51)}$. For example, quercetin and vitamin $\mathrm{C}$ were shown to induce different DNA damageresponsive signalling pathways (for example, p53 and activator protein-1 (AP-1)/NF- $\mathrm{B})$ that can subsequently enhance the expression of, for instance, NER genes ${ }^{(52,53)}$. However, results from various in vivo intervention studies have been equivocal $^{(50)}$. Therefore, further and larger studies are needed to clarify possible correlations between an individual's antioxidant capacity and DNA-repair capacity, both in the whole population as well as in several subgroups.

In the present study, we report a joint effect of genetic polymorphisms in NER-related genes and a dietary intervention on 
the phenotypically assessed NER capacity. Overall, the present results show that genetic factors have more impact on the NER capacity as compared with the effects of the blueberry and apple juice intervention. Furthermore, the common genetic polymorphism XPA G23A might be a predictor for the NER capacity, as it was not affected by the dietary intervention. Still, the present study suggests that the combined effect of multiple gene variants may be more important than the investigation of single nucleotide polymorphism in order to define an individual's DNA-repair capacity. Improved NER capacity upon dietary intervention with blueberry and apple juice was detected in individuals carrying a high number of putative low-activity alleles. In conclusion, studies of genotype-phenotype interactions seem to be helpful in the identification of susceptible subpopulations that may benefit from specific dietary interventions.

\section{Acknowledgements}

We thank Ralph W. H. Gottschalk for his assistance in the set up of the multiplex SNaPShot PCR and Stijn B. J. Lumeij for his technical support in the in vitro DNA-repair assays.

Part of the studies was supported by the European Network of Excellence (NoE) 'Environmental Cancer risk, Nutrition and Individual Susceptibility' (ECNIS), sixth Framework programme (FP6), FOOD-CT-2005-513943.

The intervention study was funded by the Netherlands Organisation for Health Research and Development (Nutrition: Health, Safety and Sustainability programme, grant no. 01412012).

The project was conceived of by J. C. S. K., R. W. L. G. and F. J. vS. The intervention was coordinated by J. C. S. K. and L. C. W. TEAC analysis was performed by L. C. W., while DNA-repair measurements were conducted by S. A. S. L. Modification of the multiplex PCR and genotyping was carried out by S. A. S. L., with help from S. H. Data analysis was carried out by S. A. S. L. and R. W. L. G., and all authors contributed in writing the manuscript.

The authors declare no conflicts of interest.

\section{References}

1. Andrew AS, Nelson HH, Kelsey KT, et al. (2006) Concordance of multiple analytical approaches demonstrates a complex relationship between DNA repair gene SNPs, smoking and bladder cancer susceptibility. Carcinogenesis 27, 1030-1037.

2. Lin J, Swan GE, Shields PG, et al. (2007) Mutagen sensitivity and genetic variants in nucleotide excision repair pathway: genotype-phenotype correlation. Cancer Epidemiol Biomarkers Prev 16, 2065-2071.

3. Shen M, Berndt SI, Rothman N, et al. (2005) Polymorphisms in the DNA nucleotide excision repair genes and lung cancer risk in Xuan Wei, China. Int J Cancer 116, 768-773.

4. Lockett KL, Snowhite IV \& Hu JJ (2005) Nucleotide-excision repair and prostate cancer risk. Cancer Lett 220, 125-135.

5. Friedberg EC (2001) How nucleotide excision repair protects against cancer. Nat Rev Cancer 1, 22-33.

6. Reardon JT, Bessho T, Kung HC, et al. (1997) In vitro repair of oxidative DNA damage by human nucleotide excision repair system: possible explanation for neurodegeneration in xeroderma pigmentosum patients. Proc Natl Acad Sci U S A 94, 9463-9468.
7. Kuraoka I, Bender C, Romieu A, et al. (2000) Removal of oxygen free-radical-induced $5^{\prime}, 8$-purine cyclodeoxynucleosides from DNA by the nucleotide excision-repair pathway in human cells. Proc Natl Acad Sci U S A 97, 3832-3837.

8. Sancar A, Lindsey-Boltz LA, Unsal-Kaçmaz K, et al. (2004) Molecular mechanisms of mammalian DNA repair and the DNA damage checkpoints. Апnи Rev Biochem 73, 39-85.

9. Sugasawa K (2008) Xeroderma pigmentosum genes: functions inside and outside DNA repair. Carcinogenesis 29, $455-465$.

10. Bootsma D, Kraemer KH, Cleaver JE, et al. (2002) Nucleotide excision repair syndromes: xeroderma pigmentosum, Cockayne syndrome, and trichothiodystrophy. In The Genetic Basis of Human Cancer, vol. 2, pp. 211-237 [B Vogelstein and KW Kinzler, editors]. New York: McGraw-Hill.

11. Zhu Y, Yang H, Chen Q, et al. (2008) Modulation of DNA damage/DNA repair capacity by XPC polymorphisms. DNA Repair (Amst) 7, 141-148.

12. Wu X, Zhao H, Wei Q, et al. (2003) XPA polymorphism associated with reduced lung cancer risk and a modulating effect on nucleotide excision repair capacity. Carcinogenesis 24, 505-509.

13. Dusinska M, Dzupinkova Z, Wsolova L, et al. (2006) Possible involvement of XPA in repair of oxidative DNA damage deduced from analysis of damage, repair and genotype in a human population study. Mutagenesis 21, 205-211.

14. Matullo G, Palli D, Peluso M, et al. (2001) XRCC1, XRCC3, $X P D$ gene polymorphisms, smoking and (32)P-DNA adducts in a sample of healthy subjects. Carcinogenesis 22, 1437-1445.

15. Shen J, Gammon MD, Terry MB, et al. (2005) Polymorphisms in XRCC1 modify the association between polycyclic aromatic hydrocarbon-DNA adducts, cigarette smoking, dietary antioxidants, and breast cancer risk. Cancer Epidemiol Biomarkers Prev 14, 336-342.

16. Cheng J, Leng S, Dai Y, et al. (2007) Association between nucleotide excision repair gene polymorphisms and chromosomal damage in coke-oven workers. Biomarkers 12, 76-86.

17. Mateuca R, Aka PV, De Boeck M, et al. (2005) Influence of $h O G G 1, X R C C 1$ and XRCC3 genotypes on biomarkers of genotoxicity in workers exposed to cobalt or hard metal dusts. Toxicol Lett 156, 277-288.

18. Mateuca RA, Roelants M, Iarmarcovai G, et al. (2008) hOGG1(326), XRCC1(399) and XRCC3(241) polymorphisms influence micronucleus frequencies in human lymphocytes in vivo. Mutagenesis 23, 35-41.

19. World Cancer Research Fund \& American Institute for Cancer Research (1997) Food, Nutrition and the Prevention of Cancer: A Global Perspective. London: World Cancer Research Fund UK.

20. Tyson J \& Mathers JC (2007) Dietary and genetic modulation of DNA repair in healthy human adults. Proc Nutr Soc 66, 42-51.

21. Collins AR, Harrington V, Drew J, et al. (2003) Nutritional modulation of DNA repair in a human intervention study. Carcinogenesis 24, 511-515.

22. Wei Q, Shen H, Wang LE, et al. (2003) Association between low dietary folate intake and suboptimal cellular DNA repair capacity. Cancer Epidemiol Biomarkers Prev 12, 963-969.

23. Tyson J, Caple F, Spiers A, et al. (2009) Inter-individual variation in nucleotide excision repair in young adults: effects of age, adiposity, micronutrient supplementation and genotype. $\mathrm{Br} \mathrm{J}$ Nutr 101, 1316-1323.

24. Langie SA, Knaapen AM, Houben JM, et al. (2007) The role of glutathione in the regulation of nucleotide excision repair during oxidative stress. Toxicol Lett 168, 302-309.

25. Gungor N, Godschalk RW, Pachen DM, et al. (2007) Activated neutrophils inhibit nucleotide excision repair in human pulmonary epithelial cells: role of myeloperoxidase. FASEB $J \mathbf{2 1}$, 2359-2367. 
26. Wilms LC, Boots AW, de Boer VC, et al. (2007) Impact of multiple genetic polymorphisms on effects of a 4-week blueberry juice intervention on ex vivo induced lymphocytic DNA damage in human volunteers. Carcinogenesis 28, 1800-1806.

27. Wilms LC, Hollman PC, Boots AW, et al. (2005) Protection by quercetin and quercetin-rich fruit juice against induction of oxidative DNA damage and formation of BPDE-DNA adducts in human lymphocytes. Mutat Res 582, 155-162.

28. Boyum A (1976) Isolation of lymphocytes, granulocytes and macrophages. Scand J Immunol Suppl. 5, 9-15.

29. Knaapen AM, Ketelslegers HB, Gottschalk RW, et al. (2004) Simultaneous genotyping of nine polymorphisms in xenobiotic-metabolizing enzymes by multiplex PCR amplification and single base extension. Clin Chem 50, 1664-1668.

30. Langie SA, Knaapen AM, Brauers KJ, et al. (2006) Development and validation of a modified comet assay to phenotypically assess nucleotide excision repair. Mutagenesis 21, 153-158.

31. Ketelslegers HB, Gottschalk RW, Godschalk RW, et al. (2006) Interindividual variations in DNA adduct levels assessed by analysis of multiple genetic polymorphisms in smokers. Cancer Epidemiol Biomarkers Prev 15, 624-629.

32. van Gils CH, Bostick RM, Stern MC, et al. (2002) Differences in base excision repair capacity may modulate the effect of dietary antioxidant intake on prostate cancer risk: an example of polymorphisms in the XRCC1 gene. Cancer Epidemiol Biomarkers Prev 11, 1279-1284.

33. Misra RR, Ratnasinghe D, Tangrea JA, et al. (2003) Polymorphisms in the DNA repair genes XPD, XRCC1, XRCC3, and APE/ $r e f-1$, and the risk of lung cancer among male smokers in Finland. Cancer Lett 191, 171-178.

34. Møller P \& Loft S (2004) Interventions with antioxidants and nutrients in relation to oxidative DNA damage and repair. Mutat Res 551, 79-89.

35. Gaivão I, Piasek A, Brevik A, et al. (2007) Comet assay-based methods for measuring DNA repair in vitro; estimates of interand intra-individual variation. Cell Biol Toxicol 25, 45-52.

36. Collins AR, Dusinska M, Horvathova E, et al. (2001) Interindividual differences in repair of DNA base oxidation, measured in vitro with the comet assay. Mutagenesis 16, 297-301.

37. Møller P, Vogel U, Pedersen A, et al. (2003) No effect of 600 grams fruit and vegetables per day on oxidative DNA damage and repair in healthy nonsmokers. Cancer Epidemiol Biomarkers Prev 12, 1016-1022.

38. Mohrenweiser HW, Xi T, Vazquez-Matias J, et al. (2002) Identification of 127 amino acid substitution variants in screening 37 DNA repair genes in humans. Cancer Epidemiol Biomarkers Prev 11, 1054-1064.

39. Zhou W, Liu G, Park S, et al. (2005) Gene-smoking interaction associations for the ERCC1 polymorphisms in the risk of lung cancer. Cancer Epidemiol Biomarkers Prev 14, 491-496.

40. Zienolddiny S, Campa D, Lind H, et al. (2006) Polymorphisms of DNA repair genes and risk of non-small cell lung cancer. Carcinogenesis 27, 560-567.

41. Matullo G, Peluso M, Polidoro S, et al. (2003) Combination of DNA repair gene single nucleotide polymorphisms and increased levels of DNA adducts in a population-based study. Cancer Epidemiol Biomarkers Prev 12, 674-677.

42. Gu J, Zhao H, Dinney CP, et al. (2005) Nucleotide excision repair gene polymorphisms and recurrence after treatment for superficial bladder cancer. Clin Cancer Res 11, 1408-1415.

43. Crew KD, Gammon MD, Terry MB, et al. (2007) Polymorphisms in nucleotide excision repair genes, polycyclic aromatic hydrocarbon-DNA adducts, and breast cancer risk. Cancer Epidemiol Biomarkers Prev 16, 2033-2041.

44. Butkiewicz D, Rusin M, Harris CC, et al. (2000) Identification of four single nucleotide polymorphisms in DNA repair genes: $X P A$ and XPB (ERCC3) in Polish population. Hum Mutat 15, 577-578.
45. Akiri G, Nahari D, Finkelstein Y, et al. (1998) Regulation of vascular endothelial growth factor (VEGF) expression is mediated by internal initiation of translation and alternative initiation of transcription. Oncogene 17, 227-236.

46. Larsen LK, Amri EZ, Mandrup S, et al. (2002) Genomic organization of the mouse peroxisome proliferator-activated receptor $\beta / \delta$ gene: alternative promoter usage and splicing yield transcripts exhibiting differential translational efficiency. Biochem $J$ 366, 767-775.

47. Vogel U, Overvad K, Wallin H, et al. (2005) Combinations of polymorphisms in $X P D, X P C$ and $X P A$ in relation to risk of lung cancer. Cancer Lett 222, 67-74.

48. Butkiewicz D, Popanda O, Risch A, et al. (2004) Association between the risk for lung adenocarcinoma and a (-4) G-to-A polymorphism in the XPA gene. Cancer Epidemiol Biomarkers Prev 13, 2242-2246.

49. Guarnieri S, Loft S, Riso P, et al. (2008) DNA repair phenotype and dietary antioxidant supplementation. Br J Nutr 99, 1018-1024.

50. Cooke MS, Evans MD, Mistry N, et al. (2002) Role of dietary antioxidants in the prevention of in vivo oxidative DNA damage. Nutr Res Rev 15, 19-42.

51. Silva JP, Gomes AC \& Coutinho OP (2008) Oxidative DNA damage protection and repair by polyphenolic compounds in PC12 cells. Eur J Pharmacol 601, 50-60.

52. Lunec J, Holloway KA, Cooke MS, et al. (2002) Urinary 8-oxo2 -deoxyguanosine: redox regulation of DNA repair in vivo? Free Radic Biol Med 33, 875-885.

53. Ye R, Goodarzi AA, Kurz EU, et al. (2004) The isoflavonoids genistein and quercetin activate different stress signaling pathways as shown by analysis of site-specific phosphorylation of ATM, p53 and histone H2AX. DNA Repair (Amst) 3, 235-244.

54. Qiao Y, Spitz MR, Shen H, et al. (2002) Modulation of repair of ultraviolet damage in the host-cell reactivation assay by polymorphic $X P C$ and $X P D / E R C C 2$ genotypes. Carcinogenesis $\mathbf{2 3}$, 295-299.

55. Vodicka P, Kumar R, Stetina R, et al. (2004) Genetic polymorphisms in DNA repair genes and possible links with DNA repair rates, chromosomal aberrations and single-strand breaks in DNA. Carcinogenesis 25, 757-763.

56. Shen J, Desai M, Agrawal M, et al. (2006) Polymorphisms in nucleotide excision repair genes and DNA repair capacity phenotype in sisters discordant for breast cancer. Cancer Epidemiol Biomarkers Prev 15, 1614-1619.

57. Ma H, Xu L, Yuan J, et al. (2007) Tagging single nucleotide polymorphisms in excision repair cross-complementing group 1 (ERCC1) and risk of primary lung cancer in a Chinese population. Pharmacogenet Genomics 17, 417-423.

58. Spitz MR, Wu X, Wang Y, et al. (2001) Modulation of nucleotide excision repair capacity by XPD polymorphisms in lung cancer patients. Cancer Res 61, 1354-1357.

59. Møller P, Wallin H, Dybdahl M, et al. (2000) Psoriasis patients with basal cell carcinoma have more repair-mediated DNA strand-breaks after UVC damage in lymphocytes than psoriasis patients without basal cell carcinoma. Cancer Lett 151, 187-192.

60. Hou SM, Ryk C, Kannio A, et al. (2003) Influence of common $X P D$ and XRCC1 variant alleles on p53 mutations in lung tumors. Environ Mol Mutagen 41, 37-42.

61. Vogel U, Olsen A, Wallin H, et al. (2005) Effect of polymorphisms in XPD, RAI, ASE-1 and ERCC1 on the risk of basal cell carcinoma among Caucasians after age 50. Cancer Detect Prev 29, 209-214.

62. Chen M, Kamat AM, Huang M, et al. (2007) High-order interactions among genetic polymorphisms in nucleotide excision repair pathway genes and smoking in modulating bladder cancer risk. Carcinogenesis 28, 2160-2165. 